\title{
Association between antihypertensive medications and risk of skin cancer in people older than 65 years: a population-based study
}

\author{
Aaron M. Drucker MD ScM, Loes Hollestein PhD, Yingbo Na MSc, Martin A. Weinstock MD PhD, Wen-Qing Li MD PhD, \\ Husam Abdel-Qadir MD PhD, An-Wen Chan MD DPhil
}

Cite as: CMAJ 2021 April 12;193:E508-16. doi: 10.1503/cmaj.201971

\begin{abstract}
BACKGROUND: The risk of skin cancer associated with antihypertensive medication use is unclear, although thiazides have been implicated in regulatory safety warnings. We aimed to assess whether use of thiazides and other antihypertensives is associated with increased rates of keratinocyte carcinoma and melanoma.
\end{abstract}

METHODS: We conducted a populationbased inception cohort study using linked administrative health data from Ontario, 1998-2017. We matched adults aged $\geq 66$ years with a first prescription for an antihypertensive medication (thiazides, angiotensin-converting enzyme inhibitors, angiotensin II receptor blockers, calcium channel blockers, $\beta$-blockers) by age and sex to 2 unexposed adults who were prescribed a non-antihypertensive medication within 30 days of the index date. We evaluated each antihypertensive class in a separate cohort study. Our primary exposure was the cumulative dose within each class, standardized according to the World Health Organization's Defined Daily Dose. Outcomes were time to first keratinocyte carcinoma, advanced keratinocyte carcinoma and melanoma.

RESULTS: The inception cohorts included a total of 302634 adults prescribed an antihypertensive medication and 605268 unexposed adults. Increasing thiazide exposure was associated with an increased rate of incident keratinocyte carcinoma (adjusted hazard ratios [HRs] per 1 Defined Annual Dose unit 1.08, 95\% confidence interval [Cl] 1.03-1.14), advanced keratinocyte carcinoma (adjusted HR 1.07, 95\% Cl 0.93-1.23) and melanoma (adjusted HR 1.34, 95\% Cl 1.01-1.78). We found no consistent evidence of association between other antihypertensive classes and keratinocyte carcinoma or melanoma.

INTERPRETATION: Higher cumulative exposure to thiazides was associated with increased rates of incident skin cancer in people aged 66 years and older. Consideration of other antihypertensive treatments in patients at high risk of skin cancer may be warranted.
K eratinocyte carcinoma (also called nonmelanoma skin cancer) includes basal and squamous cell carcinoma, the 2 most common malignancies in North America. ${ }^{1,2}$ More than 76000 and 5.4 million cases are diagnosed annually in Canada and the United States, respectively., Melanoma is the fifth most common malignancy in the US, with 83362 annual cases, 10000 deaths and incidence rates rising by $10 \%$ between 2005 and $2015 .^{3-5}$ It is estimated that there were 8000 new melanoma cases and 1300 related deaths in Canada in $2020 .{ }^{6}$ Given the high and increasing population burden of these skin cancers, identifying modifiable risk factors is important.,

Ultraviolet (UV) radiation exposure is the most important environmental risk factor for skin cancer. ${ }^{9,10}$ Medication-induced phototoxicity, in which medications interact with UV radiation to cause cellular damage in the skin, may increase the carcinogenic potential of sun exposure. ${ }^{11}$ Antihypertensive medications are used by about 1 in 5 adults, ${ }^{12}$ and thiazide diuretics, calcium channel blockers, $\beta$-blockers, angiotensin II receptor blockers (ARBs) and angiotensin-converting enzyme (ACE) inhibitors have all been reported to be phototoxic. ${ }^{11,13}$ Hydrochlorothiazide is first-line pharmacotherapy for hypertension ${ }^{14}$ and is considered the most phototoxic antihypertensive medication. ${ }^{11,13}$ It has been implicated in increasing the risk of keratinocyte carcinoma, with 2 recent case-control studies ${ }^{15,16}$ prompting Health Canada, the European Medicines Agency and the US Food and Drug Administration to issue warnings regarding prolonged use. ${ }^{17-19}$ Weaker associations have been reported between thiazides and melanoma, ${ }^{20}$ and there is conflicting evidence on the association between other antihypertensive classes and skin cancer. ${ }^{21}$ To determine whether exposure to thiazides or other antihypertensive medications is associated with skin cancer, we conducted a population-based inception cohort study. 


\section{Methods}

We followed the Reporting of Studies Conducted Using Observational Routinely Collected Health Data Statement for Pharmacoepidemiology (RECORD-PE) guideline to ensure adequate reporting. ${ }^{22-24}$

\section{Study population}

We used linked population-based administrative health data for Ontario, Canada. These data sets were linked using unique encoded identifiers and analyzed at ICES (Appendix 1, Supplemental Methods, available at www.cmaj.ca/lookup/doi/10.1503/ cmaj.201971/tab-related-content).

Fees for physician visits and hospital admissions in Ontario are covered for all residents under the Ontario Health Insurance Plan (OHIP), ${ }^{25}$ and medication costs for residents aged 65 years and older are covered by the Ontario Drug Benefit (ODB) plan. The ODB database has an accuracy rate $>99 \% .^{26}$ We limited the study to patients aged 66 years and older to allow ascertainment of incident medication exposures.

We included incident users of antihypertensive medications (exposed group) if they had a first-ever prescription for a thiazide, ACE inhibitor, ARB, calcium channel blocker or $\beta$-blocker between Jan. 1, 1998, and Dec. 31, 2016 (Appendix 1, Figure S1). The index date was defined as the date of their first filled antihypertensive prescription in ODB. We used a lookback window of at least 1 year, measured back to age 65 years or 1991 (whichever was most recent) to exclude people who had previous prescriptions for an antihypertensive, phototoxic or immunosuppressive medication for at least 90 days within any 180-day period. Because solid organ transplant recipients are at substantially higher risk for skin cancer, ${ }^{27}$ we looked back at least 17 years to 1981 to exclude any patient who received a transplant before the index date based on the Canadian Organ Replacement Register. We matched each exposed antihypertensive user to 2 nonusers (unexposed group) of the same age ( $\pm 30 \mathrm{~d}$ ) and sex who filled a prescription for any non-antihypertensive medication (excluding known phototoxic or immunosuppressive medications; listed in Appendix 1, Supplemental Methods) within 30 days of the exposed patient's index date; the date of the filled nonantihypertensive medication was the index date for the unexposed group. Nonusers could become classified as exposed if they subsequently filled an antihypertensive prescription after cohort entry.

We excluded people with a history of keratinocyte carcinoma or melanoma before the index date (lookback window of 6-25 years for keratinocyte carcinoma based on OHIP data availability since 1992; lookback window of at least 34 years to 1964 for melanoma based on Ontario Cancer Registry data availability). To account for latency and induction periods between medication exposure and its potential effect on skin cancer risk, we also excluded people with keratinocyte carcinoma or melanoma diagnosed within 365 days after the index date or with less than 1 year of follow-up owing to death or loss of OHIP coverage. The outcome observation window began after this 1-year lag.

From the overall cohort of incident users of antihypertensive medications, we created separate inception cohorts for each antihypertensive class based on the specific medication prescribed to each exposed user on their index date (i.e., their first prescribed antihypertensive medication). If multiple antihypertensive medications were prescribed on the index date, then we included the patient in the inception cohorts for each corresponding antihypertensive class. Patients contributed person-time only to the antihypertensive inception cohorts they entered on the index date; that is, although we examined each antihypertensive class as a time-varying covariate within each cohort (see Exposures and Statistical analysis sections), participants did not cross over between the separate inception cohorts after the index date.

\section{Exposures}

For each inception cohort, our exposure was the time-varying cumulative dose of the index antihypertensive class (thiazide diuretics, ACE inhibitors, ARB, calcium channel blockers, $\beta$-blockers; medications listed in Appendix 1, Supplemental Methods). To standardize the cumulative dose, we calculated a Defined Annual Dose for each medication using the World Health Organization's Defined Daily Dose (www.whocc.no/atc_ddd_index/). We divided each patient's cumulative dose by the total Defined Annual Dose (365 d × Defined Daily Dose) for each medication.

\section{Outcomes}

The primary outcome was time to first diagnosis of keratinocyte carcinoma (including basal and squamous cell carcinoma) identified using a validated OHIP claims-based algorithm (sensitivity $83 \%-85 \%$, specificity $93 \%-99 \%) .{ }^{28}$ Our secondary outcomes were time to first advanced keratinocyte carcinoma and first melanoma. We defined advanced keratinocyte carcinoma as keratinocyte carcinoma causing death (International Classification of Diseases, 9th Revision 173 or International Statistical Classification of Diseases and Related Health Problems, 10th Revision C44 listed as a cause of death in the Ontario Registrar General Death database) ${ }^{29}$ or requiring complex surgery (Appendix 1, Supplemental Methods); this definition of advanced keratinocyte carcinoma has been used in previous studies but has not been validated. ${ }^{30}$ Cases of invasive melanoma were identified from the Ontario Cancer Registry, which captures $94 \%$ of melanomas diagnosed in Ontario. ${ }^{31}$

\section{Covariates}

We obtained baseline age, sex, location of residence (urban or rural) and socioeconomic status based on residential postal code (income quintile) from the Ontario Registered Persons Database. ${ }^{32,33}$ We assessed history of hypertension before or on the index date using a validated administrative data algorithm. ${ }^{34}$ We derived the Charlson-Deyo comorbidity index using a 2-year lookback window to identify hospital discharge records in the Canadian Institute for Health Information. ${ }^{35,36}$ To account for detection bias associated with health care utilization, ${ }^{37}$ we assessed the number of outpatient and inpatient physician visits in the 12 months before the index date. To account for secular trends in prescription patterns and skin cancer diagnosis, we included the time period of the index date (1998-2000; 2001-2005; 2006-2010; 2011-2016) as a covariate. We used ODB to identify time-varying exposure (updated monthly) to immunosuppressant and other phototoxic medications for a clinically meaningful duration of at least 180 days in any 365-day period during follow-up. 


\section{Statistical analysis}

We conducted analyses separately for each of the 5 antihypertensive class inception cohorts. We used multivariable causespecific hazards regression and restricted cubic spline functions with 5 knots (5th, 27.5th, 50th, 72.5th and 95th percentiles) to model the associations between the index drug exposure and each skin cancer outcome (keratinocyte carcinoma, advanced keratinocyte carcinoma, melanoma), while accounting for the competing risk of death. The primary exposure in each analysis was the cumulative dose of the index antihypertensive class of interest, modelled as a continuous time-varying covariate. We used 0 to 0.5 Defined Annual Dose units as the lowest dose category (rather than 0 ) to avoid collinearity with an ever or never use covariate and because short-term exposure is unlikely to meaningfully increase skin cancer risk. Patients who were unexposed at baseline contributed person-time in the unexposed group; if they were later prescribed the exposure antihypertensive class (not as their first antihypertensive, by definition), subsequent person-time was attributed to the exposed group. Patients were followed from their index date until their first skin cancer, death, loss of OHIP eligibility for $\geq 90$ days (outmigration from Ontario) or Dec. 31, 2017, whichever was earliest.

Each model evaluating cumulative medication exposure included ever or never use of each antihypertensive class as a binary, time-varying covariate. The inclusion of this covariate controls for treatment selection bias (confounding by indication) due to unmeasured factors associated with the propensity to be prescribed the medications. ${ }^{38}$ In every model, we adjusted for the time-varying cumulative dose of each of the other 4 nonindex antihypertensive classes. ${ }^{38}$ We adjusted each model for the fixed baseline and time-varying covariates listed above. We estimated associations as adjusted hazard ratios (adjusted HRs) and 95\% confidence intervals $(\mathrm{Cls})$. We considered 2 -sided $p<0.05$ to be statistically significant. We tested the proportional hazards assumption for time-independent covariates in each model by checking their interaction with the logarithm of time.

In additional analyses to promote clinical interpretability, we fit the above models with cumulative Defined Annual Dose units for each medication class, as follows: 0 to $0.5,>0.5$ to 1.5 , increasing in single unit increments up to $>7.5$. We used contrast statements with orthogonal polynomial coefficients to calculate $p$ for linear trend for increasing cumulative dose categories. We also evaluated these ordinal exposures as cumulative duration of use, irrespective of the dose. In sensitivity analyses, we extended the lag time to exclude patients with their first keratinocyte carcinoma diagnosis or end of follow-up occurring within 2 and 3 years after the index date.

\section{Ethics approval}

Owing to use of routinely collected data, this project was exempt from ethics review, as authorized under section 45 of Ontario's Personal Health Information Protection Act.

\section{Results}

We identified 2630956 patients who were prescribed an antihypertensive medication between 1998 and 2016. After applying our exclusion criteria, we included a total of 302634 patients exposed to antihypertensive medications at baseline and 605268 matched unexposed patients in our inception cohorts (Figure 1). Patients exposed to antihypertensive medications but excluded because they could not be matched $(n=218614)$ tended to be older, have more preceding physician visits and have a more recent index date, but were otherwise similar to those included (Appendix 1, Table S1). Angiotensin-converting enzyme inhibitors were the most commonly first prescribed antihypertensive medication class ( $n=112723,37 \%)$, followed by

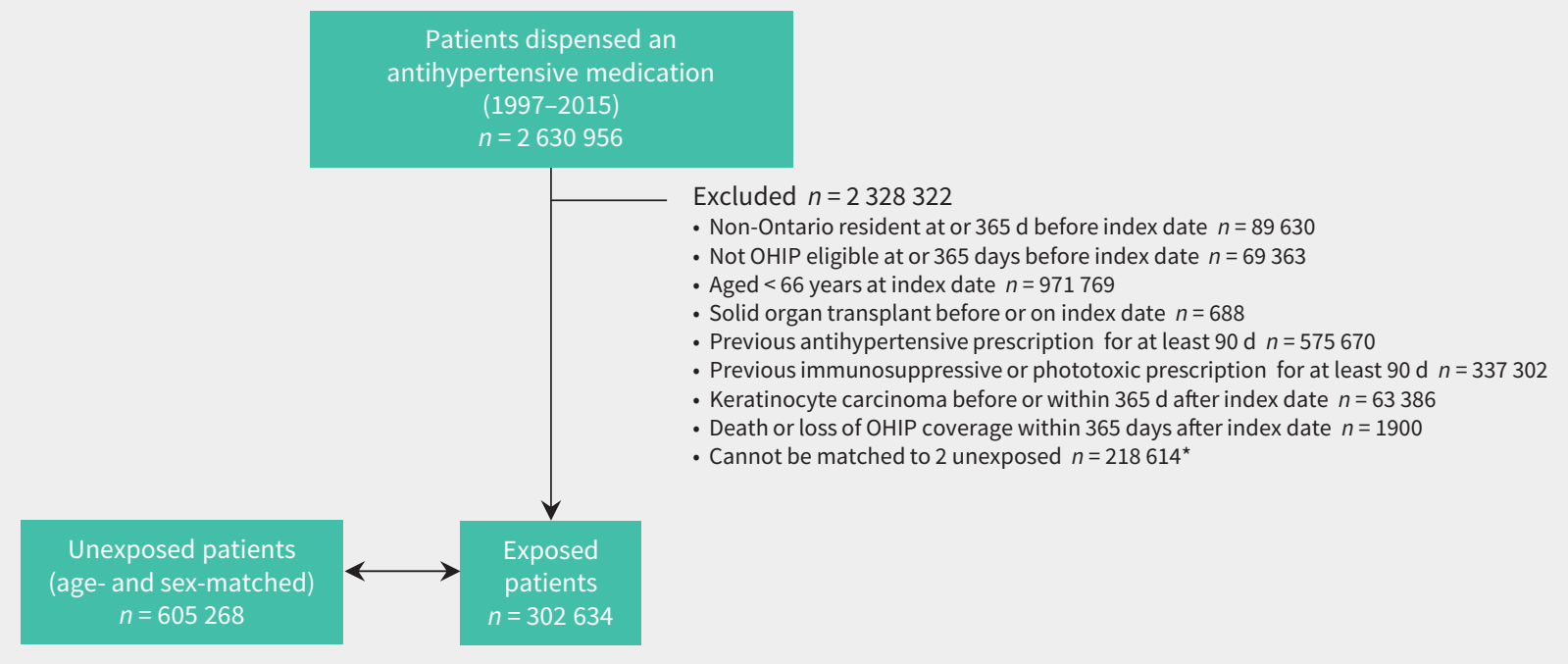

Figure 1: Patient flow diagram. Note: OHIP = Ontario Health Insurance Plan. *Baseline characteristics of new users of antihypertensive medications excluded because they could not be matched are presented in Appendix 1, Table S1 (available at www.cmaj.ca/lookup/doi/10.1503/cmaj.201971/ tab-related-content). 
thiazide diuretics ( $n=87725,29 \%$ ), $\beta$-blockers ( $n=68218,23 \%$ ), calcium channel blockers $(n=50533,17 \%)$ and ARB $(26317,9 \%)$.

Baseline characteristics for the matched thiazide inception cohort are given in Table 1. The number of physician visits and Charlson-Deyo comorbidity index at baseline were similar between exposed and matched unexposed patients, but the former were more likely to have been diagnosed with hypertension (70\% v. 23\%). Baseline characteristics for the other antihypertensive inception cohorts are in Appendix 1, Tables S2-S5.

In the thiazide inception cohort, 8768 of 87525 (10\%) originally exposed and 18706 of 175050 (11\%) matched, originally unexposed patients were diagnosed with a keratinocyte carcinoma (Appendix 1, Table S6), 1302 (1.5\%) exposed and 2559 (1.5\%) unexposed were diagnosed with an advanced keratinocyte carcinoma and 296 (0.3\%) exposed and 564 (0.3\%) unexposed were

Table 1: Baseline characteristics of patients first exposed to thiazide diuretics and matched unexposed patients*

\begin{tabular}{|c|c|c|}
\hline Characteristic & $\begin{array}{l}\text { No. }(\%) \dagger \text { of } \\
\text { patients } \\
\text { exposed to } \\
\text { thiazides at } \\
\text { index date } \\
n=87525\end{array}$ & $\begin{array}{l}\text { No. }(\%) \dagger \text { of } \\
\text { patients } \\
\text { unexposed to } \\
\text { antihypertensives } \\
\text { at index date } \\
n=175050 \ddagger\end{array}$ \\
\hline $\begin{array}{l}\text { Age, yr, at index date, } \\
\text { median (IQR) }\end{array}$ & $70(67-75)$ & $70(67-75)$ \\
\hline Sex, female, $n(\%)$ & $55241(63)$ & $110482(63)$ \\
\hline Rural residence & $13838(16)$ & $25710(15)$ \\
\hline \multicolumn{3}{|c|}{ Income quintile based on residential postal code } \\
\hline 1 (highest) & $17177(20)$ & $32467(19)$ \\
\hline 2 & $18286(21)$ & $35569(20)$ \\
\hline 3 & $17572(20)$ & $34388(20)$ \\
\hline 4 & $16763(19)$ & $34147(20)$ \\
\hline 5 (lowest) & $17396(20)$ & $37863(22)$ \\
\hline $\begin{array}{l}\text { No. of physician visits in the } 12 \text { mo } \\
\text { before the index date, } \\
\text { median (IQR) }\end{array}$ & $9(4-16)$ & $9(5-16)$ \\
\hline \multicolumn{3}{|l|}{ Charlson-Deyo comorbidity index } \\
\hline 0 & $81276(93)$ & $165189(94)$ \\
\hline 1 & $3044(3)$ & $4201(2)$ \\
\hline$\geq 2$ & $3205(4)$ & $5660(3)$ \\
\hline $\begin{array}{l}\text { Hypertension diagnosed on or } \\
\text { before index date }\end{array}$ & $61359(70)$ & $40448(23)$ \\
\hline \multicolumn{3}{|l|}{ Year of index date } \\
\hline $1998-2000$ & $28967(33)$ & $57934(33)$ \\
\hline 2001-2005 & $27068(31)$ & $54136(31)$ \\
\hline 2006-2010 & 16356 (19) & 32712 (19) \\
\hline 2011-2016 & 15134 (17) & 30268 (17) \\
\hline \multicolumn{3}{|c|}{$\begin{array}{l}\text { Note: IQR = interquartile range. } \\
\text { *Baseline characteristics for patients first exposed to other antihypertensive } \\
\text { medications are found in Appendix } 1 \text {, Tables S1-4 (available at www.cmaj.ca/lookup/ } \\
\text { doi/10.1503/cmaj.201971/tab-related-content). } \\
\text { †Unless otherwise stated. } \\
\$ 25 \% \text { became exposed to thiazides during follow-up. }\end{array}$} \\
\hline
\end{tabular}

diagnosed with a melanoma. There were 2426593 total personyears of follow-up (median 8.9 years, interquartile range 4.613.7), with 40 deaths attributed to keratinocyte carcinoma. In each baseline group, $34 \%$ of patients died of causes unrelated to keratinocyte carcinoma during follow-up.

Increasing thiazide exposure was associated with increased rates of incident keratinocyte carcinoma (adjusted HR per Defined Annual Dose unit increase 1.08, 95\% Cl 1.03-1.14) and melanoma (adjusted HR 1.34, 95\% Cl 1.01-1.78) (Appendix 1, Table S7). The association between thiazide exposure and advanced keratinocyte carcinoma was of similar magnitude to the association with keratinocyte carcinoma overall, but with wider confidence intervals (adjusted HR 1.07, 95\% Cl 0.93-1.23). Restricted cubic spline curves show strengthening of the association between thiazides and keratinocyte carcinoma (Figure 2) and advanced keratinocyte carcinoma (Figure 3) with increasing cumulative exposure, whereas effect estimates became increasingly imprecise for melanoma beyond 10 Defined Annual Dose units (Figure 4). In the analysis with thiazides modelled as an ordinal exposure, patients exposed to $>7.5$ Defined Annual Dose units had a $44 \%$ higher rate of keratinocyte carcinoma (adjusted HR 1.44, 95\% Cl 1.35-1.54, Appendix 1, Table S8), 52\% higher rate of advanced keratinocyte carcinoma (adjusted HR $1.52[95 \% \mathrm{Cl}$ 1.29 to 1.79], Appendix 1, Table S9) and 60\% higher rate of melanoma (1.60 [95\% Cl 1.10-2.32], Appendix 1, Table S10) compared with 0-0.5 Defined Annual Dose units.

Along with increasing dose of thiazides, other variables independently associated with keratinocyte carcinoma in the inception cohort for thiazides included age (per additional year, adjusted HR 1.02, 95\% Cl 1.02 adjusted 1.02), male sex (adjusted HR 1.42, 95\% Cl 1.38-1.45), rural residence (adjusted HR 1.12, $95 \% \mathrm{Cl} 1.08-1.16)$, being in the highest 2 income quintiles (adjusted HR 1.32, 95\% 1.29-1.36), immunosuppressant drug use (adjusted HR 1.38, 95\% Cl 1.29-1.48) and phototoxic drug use (adjusted HR 1.09, 95\% Cl 1.06-1.12) (Appendix 1, Table S11).

In the inception cohorts for the other antihypertensive classes, associations between other antihypertensive classes and keratinocyte carcinoma, advanced keratinocyte carcinoma and melanoma were small, inconsistent or statistically nonsignificant (Figures 2-4; Appendix 1, Table S7). Results were similar in secondary analyses where exposures were modelled as ordinal cumulative duration variables (Appendix 1, Tables S8-10), and in sensitivity analyses that excluded patients with keratinocyte carcinoma diagnoses or end of follow-up within 2 and 3 years after starting their first antihypertensive medication (Appendix 1, Table S12).

\section{Interpretation}

In this population-based inception cohort study among older adults in Ontario, we found a significant increase in the rate of keratinocyte carcinoma and melanoma associated with increasing cumulative thiazide diuretic use. Exposure to other antihypertensive classes, which are not thought to be as phototoxic, ${ }^{11,13}$ either did not affect the rate of keratinocyte carcinoma and melanoma or had inconsistent or weak associations. 
Our finding that thiazide diuretics increased the rate of keratinocyte carcinoma is consistent in direction with recent casecontrol studies from Denmark. ${ }^{15,16}$ The authors found that cumulative hydrochlorothiazide dosages over $50000 \mathrm{mg}$ (equivalent to 5.5 Defined Annual Dose units) were associated with $29 \%$ and
$400 \%$ increased odds of basal cell carcinoma and squamous cell carcinoma, respectively. ${ }^{15}$ In a meta-analysis evaluating the association between thiazide diuretics and keratinocyte carcinoma, thiazide diuretics were associated with increased risk of both basal and squamous cell carcinoma. ${ }^{20}$ Our finding of an
A

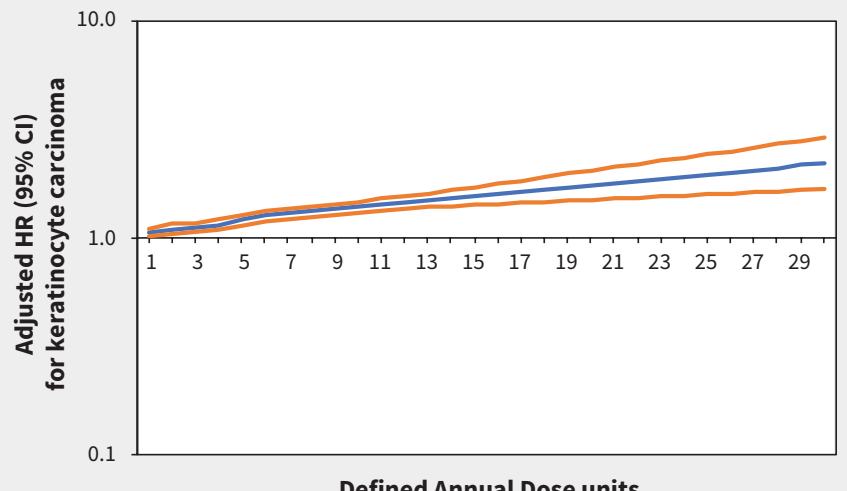

C

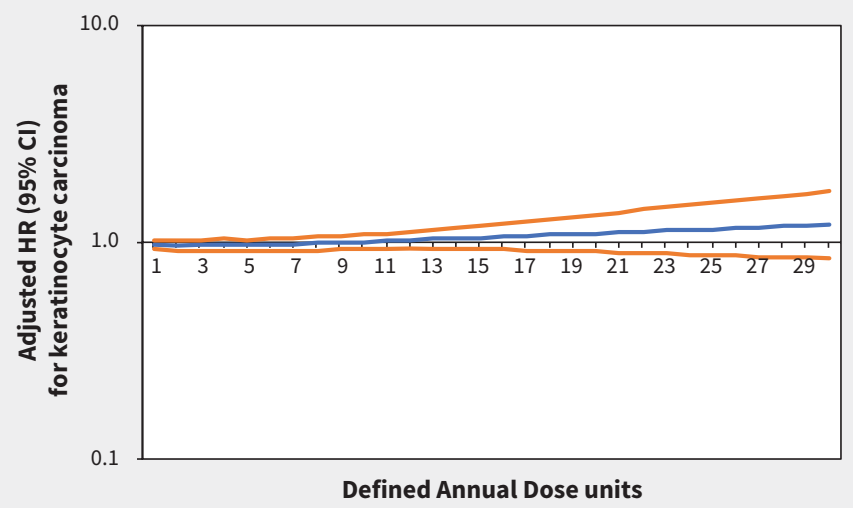

E

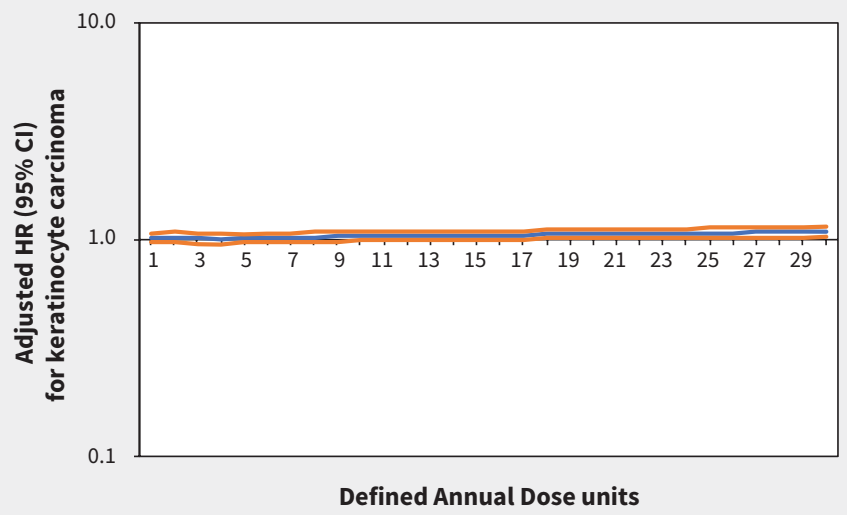

B

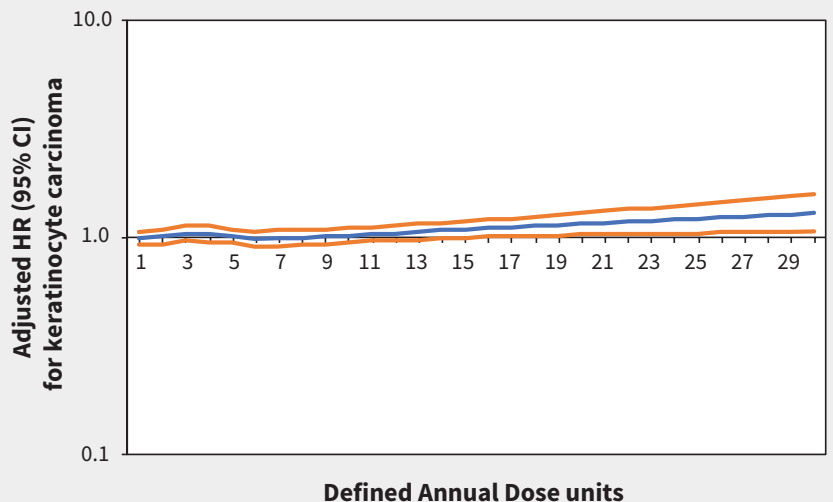

D

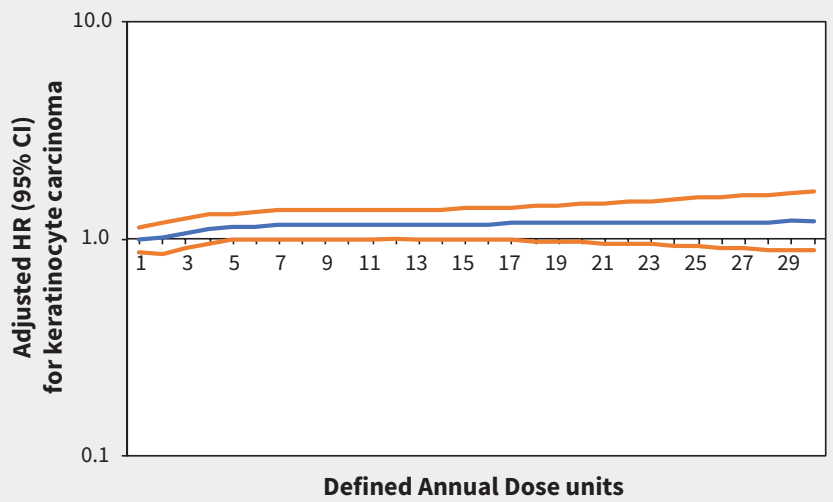

Figure 2: Rate of keratinocyte carcinoma associated with increasing cumulative dose of (A) thiazide diuretics (adjusted hazard ratio [HR] per unit increase 1.08, 95\% confidence interval [Cl] 1.03-1.14), (B) calcium channel blockers (adjusted HR 1.03, 95\% Cl 0.95-1.13), (C) $\beta$-blockers (adjusted HR 0.98, 95\% Cl 0.93-1.04), (D) angiotensin II receptor blockers (adjusted HR 1.09, 95\% Cl 0.91-1.29) and (E) angiotensin-converting enzyme inhibitors (adjusted HR 1.08, 95\% Cl 0.95-1.06) in Ontario. Note: $y$-axes are on a $\log _{10}$ scale. Blue lines represent the adjusted HR and orange lines represent the 95\% Cl with 0-0.5 Defined Annual Dose units as the reference. Models are adjusted for age, sex, rurality, income according to postal code (quintile), number of physician visits, Charlson-Deyo comorbidity index, history of hypertension, year of index date, immunosuppressive medication use (timevarying), phototoxic medication use (time-varying), cumulative dosage or duration of other antihypertensive classes (time-varying) and ever use of each antihypertensive class (time-varying). 
association between thiazide use and melanoma is also consistent in direction with that meta-analysis, which found an odds ratio of $1.14 .^{20}$ Many of the included studies were limited by deficiency of data on cumulative thiazide dosage, immortal time bias, a lack of accounting for polypharmacy and treatment selection bias. ${ }^{15,16,20,39-54}$ In a systematic review of keratinocyte

A

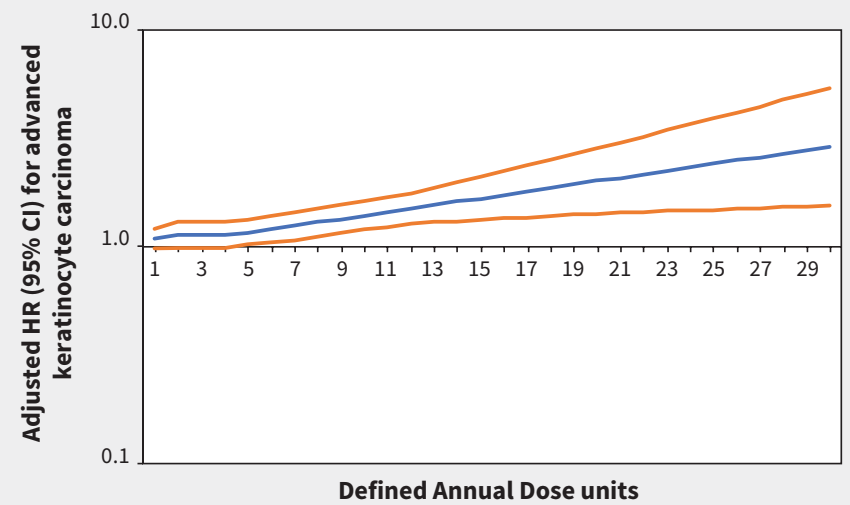

C

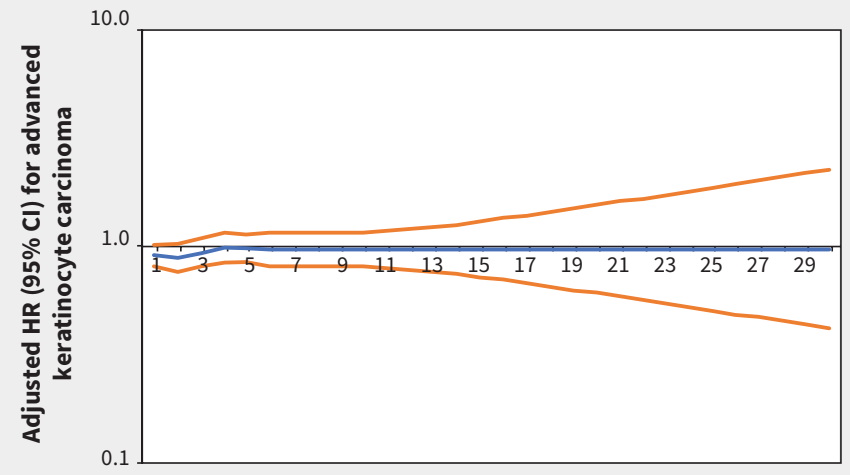

Defined Annual Dose units

E

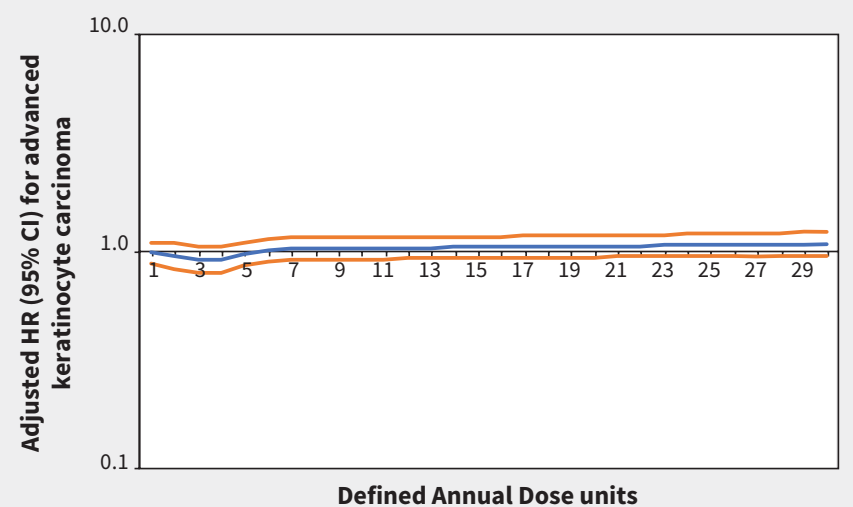

carcinoma risk associated with all antihypertensive classes, use of $\beta$-blockers and calcium channel blockers was associated with a slightly increased risk for basal (odds ratio 1.09 for $\beta$-blockers and 1.15 for calcium channel blockers) but not squamous cell carcinoma. ${ }^{21}$ Findings for ACE inhibitors and ARBs were heterogeneous. ${ }^{21}$

\section{B}

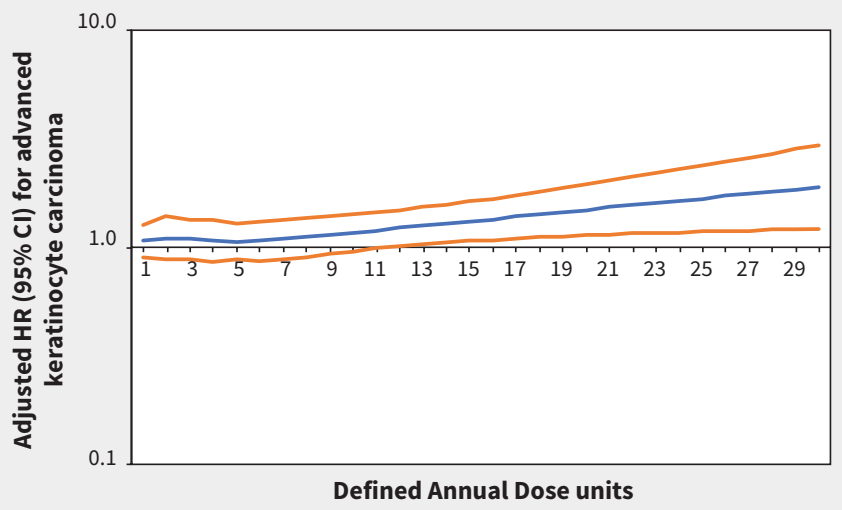

D

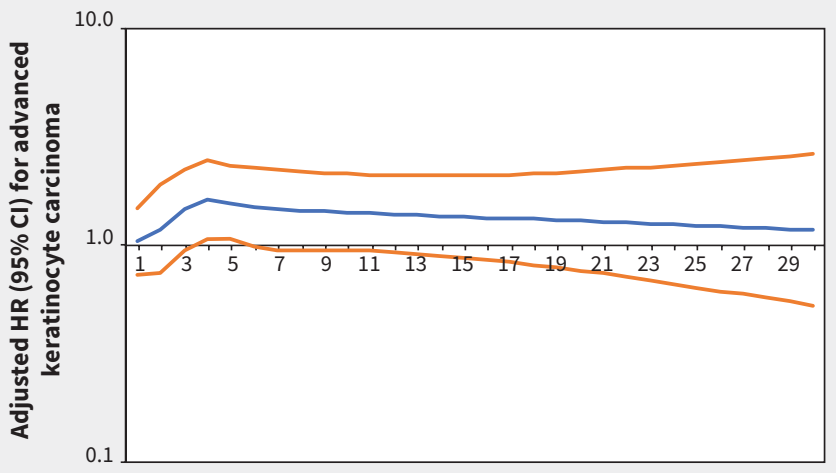

Defined Annual Dose units

Figure 3: Rate of advanced keratinocyte carcinoma associated with increasing cumulative dose of (A) thiazide diuretics (adjusted hazard ratio [HR] per unit increase 1.07, 95\% confidence interval [Cl] 0.93-1.23), (B) calcium channel blockers (adjusted HR 1.08, 95\% Cl 0.86-1.36), (C) $\beta$-blockers (adjusted HR 0.95, 95\% Cl 0.82-1.10), (D) angiotensin II receptor blockers (adjusted HR 1.49, 95\% Cl 0.93-2.39) and (E) angiotensin-converting enzyme inhibitors (adjusted HR 0.91, 95\% Cl 0.79-1.06) in Ontario. Note: $y$-axes are on a $\log _{10}$ scale. Blue lines represent the adjusted HR and orange lines represent the 95\% Cl with 0-0.5 Defined Annual Dose units as the reference. Models are adjusted for age, sex, rurality, income according to postal code (quintile), number of physician visits, Charlson-Deyo comorbidity index, history of hypertension, year of index date, immunosuppressive medication use (timevarying), phototoxic medication use (time-varying), cumulative dosage or duration of other antihypertensive classes (time-varying) and ever use of each antihypertensive class (time-varying). 
Our study addresses limitations of previous studies, including having relevant comparison groups, time-varying cumulative exposure variables, large sample size and standardized measurement of cumulative dose. We also adjusted for concomitant use of other antihypertensive medication $5^{55}$ and adjusted for treatment selection bias by including a binary ever or never use variable for each antihypertensive class. ${ }^{38}$
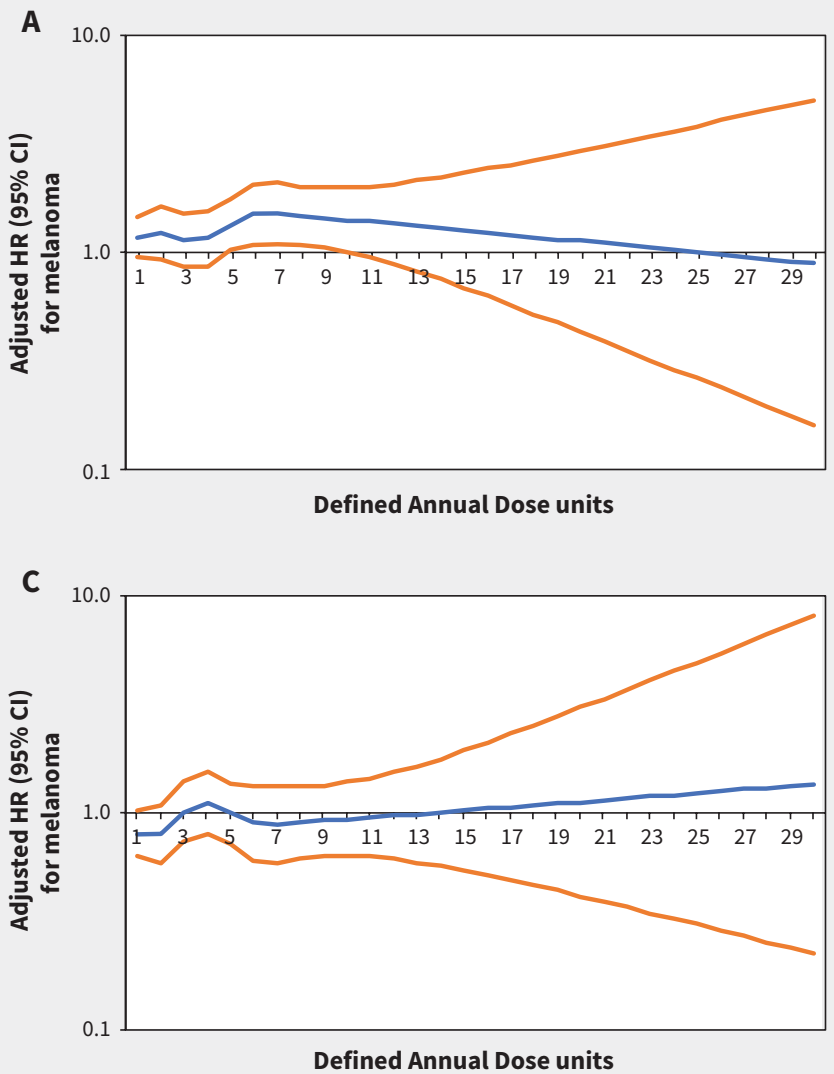

Defined Annual Dose units

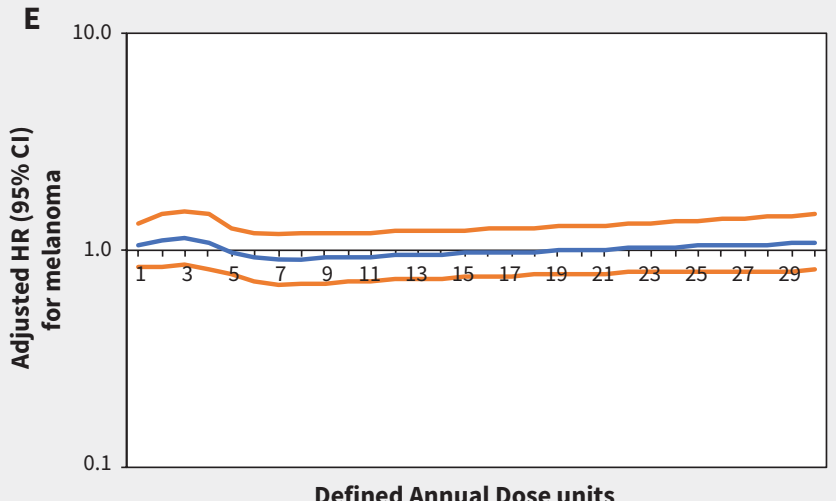

\section{Limitations}

We assessed 3 different outcomes for 5 separate antihypertensive drug cohorts, and the multiple comparisons could have inflated the chance of a false-positive result. Inherent in the observational design is the potential for unmeasured confounding, although we adjusted for treatment selection bias, as noted above. For example, our administrative data do not include UV radiation exposure, race

B

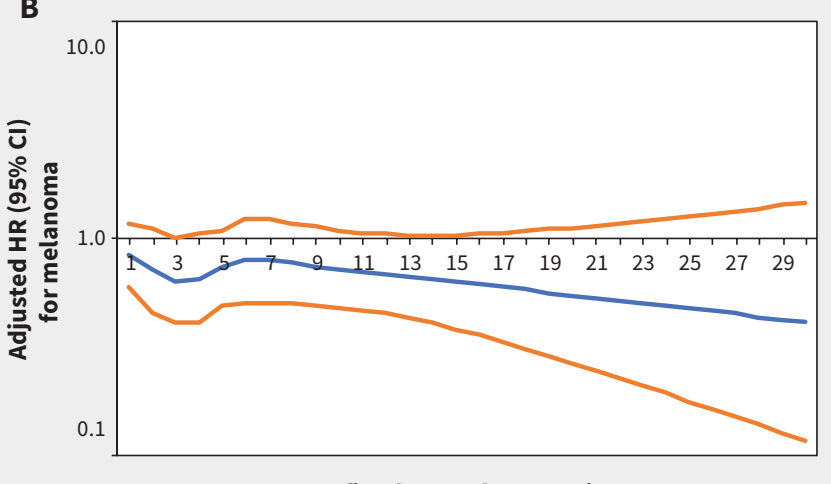

Defined Annual Dose units

D

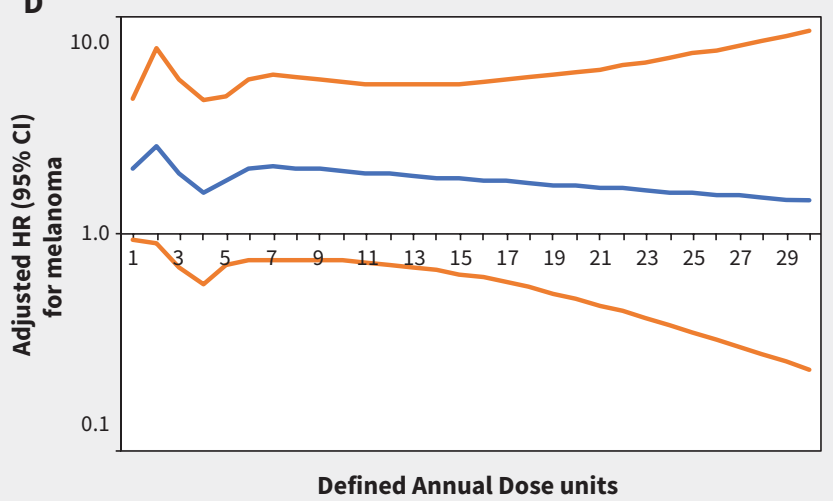

Figure 4: Rate of melanoma associated with increasing cumulative dose of (A) thiazide diuretics (adjusted hazard ratio [HR] per unit increase 1.34, 95\% confidence interval [CI] 1.01-1.78), (B) calcium channel blockers (adjusted HR 0.86, 95\% Cl 0.55-1.36), (C) $\beta$-blockers (adjusted HR 0.76, 95\% $\mathrm{Cl} 0.55-1.04$ ), (D) angiotensin II receptor blockers (adjusted HR 1.73, 95\% Cl 0.63-4.74) and (E) angiotensin-converting enzyme inhibitors (adjusted $\mathrm{HR} 0.98,95 \% \mathrm{Cl} 0.73-1.32$ ) in Ontario. Note: $\mathrm{y}$-axes are on a $\log _{10}$ scale. Blue lines represent the adjusted $\mathrm{HR}$ and orange lines represent the $95 \% \mathrm{Cl}$ with 0-0.5 Defined Annual Dose units as the reference. Models are adjusted for age, sex, rurality, income according to postal code (quintile), number of physician visits, Charlson-Deyo comorbidity index, history of hypertension, year of index date, immunosuppressive medication use (timevarying), phototoxic medication use (time-varying), cumulative dosage or duration of other antihypertensive classes (time-varying) and ever use of each antihypertensive class (time-varying). 
or skin type, yet in the ethnically diverse population of Ontario $29 \%$ of the population identify as visible minorities. ${ }^{56}$ We used a new-user design, but it is possible that patients were exposed to antihypertensive medications before our minimum 1-year lookback window, although these are chronic disease medications that are unlikely to be stopped for such a prolonged time. Our study was restricted to older adults; associations between antihypertensive medications and skin cancer in younger populations may be different owing to their lower lifetime UV radiation exposure and keratinocyte carcinoma incidence. We were unable to identify squamous and basal cell carcinomas separately. Detection bias may partly explain the association between thiazides and skin cancer; ${ }^{37}$ we adjusted for physician visits and are reassured by the lack of association between the other antihypertensive classes and skin cancer.

\section{Conclusion}

We found consistent dose-dependent increases in skin cancer risk associated with thiazides but not with other antihypertensive classes. Although not evaluated in our study, interventions that may decrease the burden of skin cancer for patients taking thiazide diuretics include sun protection and monitoring for early detection of skin cancer. Clinicians may consider alternatives to thiazide diuretics to treat hypertension in patients at high risk for skin cancer. Future studies should replicate our analyses in other populations and geographies, as skin cancer risk differs by latitude even within Canada. ${ }^{57,58}$ Studies on the impact of current regulatory safety warnings and whether they or other interventions decrease the burden of skin cancer associated with thiazide use are needed.

\section{References}

1. Rogers HW, Weinstock MA, Feldman SR, et al. Incidence estimate of nonmelanoma skin cancer (keratinocyte carcinomas) in the U.S. population, 2012. JAMA Dermatol 2015;151:1081-6.

2. The economic burden of skin cancer in Canada: current and projected - final report. Toronto: Canadian Partnership Against Cancer; 2010.

3. Paulson KG, Gupta D, Kim TS, et al. Age-specific incidence of melanoma in the United States. JAMA Dermatol 2020;156:57-64.

4. Siegel RL, Miller KD, Jemal A. Cancer statistics, 2017. CA Cancer J Clin 2017;67:7-30.

5. Glazer AM, Winkelmann RR, Farberg AS, et al. Analysis of trends in US melanoma incidence and mortality. JAMA Dermatol 2017;153:225-6.

6. Brenner DR, Weir HK, Demers AA, et al.; Canadian Cancer Statistics Advisory Committee. Projected estimates of cancer in Canada in 2020. CMAJ 2020;192:E199-205.

7. Abbas M, Kalia S. Trends in non-melanoma skin cancer (basal cell carcinoma and squamous cell carcinoma) in Canada: a descriptive analysis of available data. J Cutan Med Surg 2016;20:166-75.

8. Kachuri L, De P, Ellison LF, et al.; Advisory Committee on Canadian Cancer Statistics. Cancer incidence, mortality and survival trends in Canada, 1970-2007. Chronic Dis Inj Can 2013;33:69-80.

9. Albert MR, Weinstock MA. Keratinocyte carcinoma. CA Cancer J Clin 2003;53:292-302.

10. Gilchrest BA, Eller MS, Geller AC, et al. The pathogenesis of melanoma induced by ultraviolet radiation. N Engl J Med 1999;340:1341-8.

11. Blakely KM, Drucker AM, Rosen CF. Drug-induced photosensitivity: an update - culprit drugs, prevention and management. Drug Saf 2019;42:827-47.

12. Dorans KS, Mills KT, Liu Y, et al. Trends in prevalence and control of hypertension according to the 2017 American College of Cardiology/American Heart Association (ACC/AHA) guideline. J Am Heart Assoc 2018;7:e008888.

13. Drucker AM, Rosen CF. Drug-induced photosensitivity: culprit drugs, management and prevention. Drug Saf 2011;34:821-37.

14. Leung AA, Daskalopoulou SS, Dasgupta K, et al. Hypertension Canada. Hypertension Canada's 2017 guidelines for diagnosis, risk assessment, prevention, and treatment of hypertension in adults. Can J Cardiol 2017;33:557-76.

15. Pedersen SA, Gaist D, Schmidt SAJ, et al. Hydrochlorothiazide use and risk of nonmelanoma skin cancer: a nationwide case-control study from Denmark. J Am Acad Dermatol 2018;78:673-81.e9.
16. Pottegård $\mathrm{A}$, Hallas J, Olesen $\mathrm{M}$, et al. Hydrochlorothiazide use is strongly associated with risk of lip cancer. J Intern Med 2017;282:322-31.

17. PRAC recommendations on signals: adopted at the 3-6 September 2018 PRAC meeting. Amsterdam (The Netherlands): European Medicines Agency; 2018.

18. Summary safety review: hydrochlorothiazide. Drug and Health Product Register; modified 2020 Nov. 13. Available: https://hpr-rps.hres.ca/reg-content/summary -safety-review-detail.php?lang=en\&linkID=SSR00215 (accessed 2019 Nov. 14).

19. FDA approves label changes to hydrochlorothiazide to describe small risk of nonmelanoma skin cancer. Silver Spring (MD): US Food and Drug Administration; 2020 Aug. 20. Available: www.fda.gov/drugs/drug-safety-and-availability/fda -approves-label-changes-hydrochlorothiazide-describe-small-risk-non-melanoma -skin-cancer (accessed 2020 Aug. 24).

20. Shin D, Lee ES, Kim J, et al. Association between the use of thiazide diuretics and the risk of skin cancers: a meta-analysis of observational studies. J Clin Med Res 2019;11:247-55.

21. Tang H, Fu S, Zhai S, et al. Use of antihypertensive drugs and risk of keratinocyte carcinoma: a meta-analysis of observational studies. Pharmacoepidemiol Drug Saf 2018;27:279-88.

22. Langan SM, Schmidt SA, Wing K, et al. The reporting of studies conducted using observational routinely collected health data statement for pharmacoepidemiology (RECORD-PE). BMJ 2018;363:k3532.

23. Benchimol El, Smeeth L, Guttmann A, et al.; RECORD Working Committee. The REporting of studies Conducted using Observational Routinely-collected health Data (RECORD) statement. PLoS Med 2015;12:e1001885.

24. von Elm E, Altman DG, Egger M, et al.; STROBE Initiative. The Strengthening the Reporting of Observational Studies in Epidemiology (STROBE) statement: guidelines for reporting observational studies. PLoS Med 2007;4:e296.

25. Williams J, Young W. Appendix I: A summary of studies on the quality of health care administrative databases in Canada. In: The ICES Practice Atlas, 2nd edition Patterns of Health Care in Ontario. Ottawa: Canadian Medical Association; 1996;339.

26. Levy AR, O'Brien BJ, Sellors C, et al. Coding accuracy of administrative drug claims in the Ontario Drug Benefit database. Can J Clin Pharmacol 2003;10:67-71.

27. Park CK, Fung K, Austin PC, et al. Incidence and risk factors of keratinocyte carcinoma after first solid organ transplant in Ontario, Canada. JAMA Dermatol 2019;155:1041-8.

28. Chan A-W, Fung K, Tran JM, et al. Application of recursive partitioning to derive and validate a claims-based algorithm for identifying keratinocyte carcinoma (nonmelanoma skin cancer). JAMA Dermatol 2016;152:1122-7.

29. Brenner DR, Tammemägi MC, Bull SB, et al. Using cancer registry data: agreement in cause-of-death data between the Ontario Cancer Registry and a longitudinal study of breast cancer patients. Chronic Dis Can 2009;30:16-9.

30. Chan A-W, Fung K, Austin PC, et al. Improved keratinocyte carcinoma outcomes with annual dermatology assessment after solid organ transplantation: population-based cohort study. Am J Transplant 2019;19:522-31.

31. Tran JM, Schwartz R, Fung K, et al. Comprehensive capture of cutaneous melanoma by the Ontario Cancer Registry: validation study using community pathology reports. Cancer Causes Control 2016;27:137-42.

32. Glazier RH, Creatore MI, Agha MM, et al.; Inner City Toronto Time Trends Working Group. Socioeconomic misclassification in Ontario's Health Care Registry. Can J Public Health 2003;94:140-3.

33. Wilkins R. Use of postal codes and addresses in the analysis of health data. Health Rep 1993;5:157-77.

34. Tu K, Campbell NR, Chen Z-L, et al. Accuracy of administrative databases in identifying patients with hypertension. Open Med 2007;1:e18-26.

35. Deyo RA, Cherkin DC, Ciol MA. Adapting a clinical comorbidity index for use with ICD-9-CM administrative databases. J Clin Epidemiol 1992;45:613-9.

36. Chen G, Lix L, Tu K, et al.; Hypertension Outcome and Surveillance Team. Influence of using different databases and 'look back' intervals to define comorbidity profiles for patients with newly diagnosed hypertension: implications for health services researchers. PLoS One 2016;11:e0162074.

37. Drucker AM, Li W-Q, Savitz DA, et al. Association between health maintenance practices and skin cancer risk as a possible source of detection bias. JAMA Dermatol 2019;155:353-7.

38. Farran B, McGurnaghan S, Looker HC, et al. Modelling cumulative exposure for inference about drug effects in observational studies. Pharmacoepidemiol Drug Saf 2017;26:1527-33.

39. Beiderbeck-Noll AB, Sturkenboom MCJM, van der Linden PD, et al. Verapamil is associated with an increased risk of cancer in the elderly: the Rotterdam study. Eur J Cancer 2003;39:98-105.

40. Christian JB, Lapane KL, Hume AL, et al. VATTC Trial. Association of ACE inhibitors and angiotensin receptor blockers with keratinocyte cancer prevention in the randomized VATTC trial. J Natl Cancer Inst 2008;100:1223-32. 
41. de Vries E, Trakatelli M, Kalabalikis D, et al. EPIDERM Group. Known and potential new risk factors for skin cancer in European populations: a multicentre case-control study. Br J Dermatol 2012;167(Suppl 2):1-13.

42. Friis S, Sørensen HT, Mellemkjaer L, et al. Angiotensin-converting enzyme inhibitors and the risk of cancer: a population-based cohort study in Denmark. Cancer 2001;92:2462-70.

43. Hole DJ, Gillis CR, McCallum IR, et al. Cancer risk of hypertensive patients taking calcium antagonists. J Hypertens 1998;16:119-24.

44. Hole DJ, Hawthorne VM, Isles CG, et al. Incidence of and mortality from cancer in hypertensive patients. BMJ 1993;306:609-11.

45. Jensen AØ, Thomsen HF, Engebjerg MC, et al. Use of photosensitising diuretics and risk of skin cancer: a population-based case-control study. Br J Cancer 2008;99: 1522-8.

46. Kaae J, Boyd HA, Hansen AV, et al. Photosensitizing medication use and risk of skin cancer. Cancer Epidemiol Biomarkers Prev 2010;19:2942-9.

47. Karagas MR, Stukel TA, Umland V, et al. Reported use of photosensitizing medications and basal cell and squamous cell carcinoma of the skin: results of a population-based case-control study. J Invest Dermatol 2007;127:2901-3.

48. Lindholm LH, Anderson H, Ekbom T, et al. Relation between drug treatment and cancer in hypertensives in the Swedish Trial in Old Patients with Hypertension 2: a 5-year, prospective, randomised, controlled trial. Lancet 2001;358: 539-44.

49. Moscarelli L, Zanazzi M, Mancini G, et al. Keratinocyte cancer prevention with ACE inhibitors, angiotensin receptor blockers or their combination in renal transplant recipients. Clin Nephrol 2010;73:439-45.
50. Nardone B, Majewski S, Kim AS, et al. Melanoma and non-melanoma skin cancer associated with angiotensin-converting-enzyme inhibitors, angiotensin-receptor blockers and thiazides: a matched cohort study. Drug Saf 2017;40:249-55.

51. Pottegård A, Pedersen SA, Schmidt SAJ, et al. Use of hydrochlorothiazide and risk of skin cancer: a nationwide Taiwanese case-control study. Br J Cancer 2019;121:973-8.

52. Robinson SN, Zens MS, Perry AE, et al. Photosensitizing agents and the risk of non-melanoma skin cancer: a population-based case-control study. J Invest Dermatol 2013;133:1950-5.

53. Ruiter R, Visser LE, Eijgelsheim M, et al. High-ceiling diuretics are associated with an increased risk of basal cell carcinoma in a population-based follow-up study. Eur J Cancer 2010;46:2467-72.

54. Schmidt SAJ, Schmidt M, Mehnert F, et al. Use of antihypertensive drugs and risk of skin cancer. J Eur Acad Dermatol Venereol 2015;29:1545-54.

55. Campbell NRC, McAlister FA, Duong-Hua M, et al. Polytherapy with two or more antihypertensive drugs to lower blood pressure in elderly Ontarians. Room for improvement. Can J Cardiol 2007;23:783-7.

56. 2016 census highlights: Factsheet 9. Toronto: Queen's Printer for Ontario; modified 2017 Nov. 21. Available: www.fin.gov.on.ca/en/economy/ demographics/census/cenhi16-9.html (accessed 2020 Feb. 27).

57. Ghazawi FM, Cyr J, Darwich R, et al. Cutaneous malignant melanoma incidence and mortality trends in Canada: a comprehensive population-based study. $J$ Am Acad Dermatol 2019;80:448-59.

58. Ghazawi FM, Le M, Lagacé F, et al. Incidence, mortality, and spatiotemporal distribution of cutaneous malignant melanoma cases across Canada. J Cutan Med Surg 2019;23:394-412.
Competing interests: Aaron Drucker reports receiving consulting fees from Sanofi, RTI Health Solutions, Eczema Society of Canada and Canadian Agency for Drugs and Technology in Health and honoraria from CME Outfitters. Dr. Drucker's institutions have received educational grants from Sanofi (Women's College Hospital ) and research grants from Sanofi and Regeneron (Brown University). Martin Weinstock has received consulting fees from AbbVie and Almirall. Husam Abdel-Qadir reports receiving personal fees from Amgen Canada and from the Canadian Vigour Centre, for time spent on an end-point adjudication committee for the THEMIS clinical trial. Dr. Abdel-Qadir also reports receiving grants from the Heart and Stroke Foundation of Canada, Canadian Institutes of Health Research, and the Canadian Cardiovascular Society. No other competing interests were declared.

This article has been peer reviewed.

Affiliations: Divisions of Dermatology (Drucker, Chan) and Cardiology (Abdel-Qadir), Department of Medicine, University of Toronto; Department of Medicine and Women's College Research Institute (Drucker, Abdel-Qadir, Chan), Women's College Hospital, Toronto, Ont.; Department of Dermatology (Drucker, Weinstock, Li), Brown University, Providence, Rl; Erasmus MC Cancer Institute (Hollestein), Rotterdam, The Netherlands; Department of Research (Hollestein), Netherlands Comprehensive Cancer Center (IKNL), Utrecht, The Netherlands; ICES Central (Drucker, Abdel-Qadir) and ICES University of Toronto (Na, Chan), Toronto, Ont.; Department of Cancer Epidemiology (Li), Peking University Cancer Hospital \& Institute, China

Contributors: All of the authors contributed to the conception and design of the work. All of the authors contributed to the acquisition, analysis and interpretation of data. Aaron Drucker drafted the manuscript. All of the authors revised the manuscript critically for important intellectual content, gave final approval of the version to be published and agreed to be accountable for all aspects of the work.

Content licence: This is an Open Access article distributed in accordance with the terms of the Creative Commons Attribution (CC BY-NC-ND 4.0) licence, which permits use, distribution and reproduction in any medium, provided that the original publication is properly cited, the use is noncommercial (i.e., research or educational use), and no modifications or adaptations are made. See: https://creativecommons.org/ licenses/by-nc-nd/4.0/
Funding: This work was funded by an operating grant from the Canadian Dermatology Foundation; the funder had no role in the design, conduct, interpretation of or decision to publish the study.

Data sharing: The data set from this study is held securely in coded form at ICES. While data sharing agreements prohibit ICES from making the data set publicly available, access may be granted to those who meet prespecified criteria for confidential access, available at www.ices.on.ca/ DAS. The full dataset creation plan and underlying analytic code are available from the authors upon request, understanding that the computer programs may rely upon coding templates or macros that are unique to ICES and are therefore either inaccessible or may require modification.

Acknowledgement: The authors thank Dr. Allan Detsky for his input on a draft of this manuscript.

Disclaimer: This study was supported by ICES, which is funded by an annual grant from the Ontario Ministry of Health and Long-Term Care (MOHLTC). This study also received funding from an operating grant from the Canadian Dermatology Foundation. The analyses, conclusions, opinions and statements expressed herein are solely those of the authors and do not reflect those of the funding or data sources; no endorsement is intended or should be inferred. Parts of this material are based on data and/or information compiled and provided by $\mathrm{ClHI}$. However, the analyses, conclusions, opinions and statements expressed in the material are those of the author(s), and not necessarily those of $\mathrm{CIHI}$. We thank IMS Brogan Inc. for use of their Drug Information Database. Parts of this material are based on data and information provided by Cancer Care Ontario (CCO). The opinions, results, view, and conclusions reported in this paper are those of the authors and do not necessarily reflect those of CCO. No endorsement by $\mathrm{CCO}$ is intended or should be inferred. Parts of this report are based on Ontario Registrar General information on deaths, the original source of which is ServiceOntario. The views expressed therein are those of the author and do not necessarily reflect those of Ontario Registrar General or Ministry of Government Services. As a prescribed entity under Ontario's privacy legislation, ICES is authorized to collect and use health care data for the purposes of health system analysis, evaluation and decision support. Secure access to these data is governed by policies and procedures that are approved by the Information and Privacy Commissioner of Ontario.

Accepted: Feb. 22, 2021

Correspondence to: An-Wen Chan, anwen.chan@utoronto.ca 